\title{
SÉRIE FOTOGRÁFICA: RETRATOS DE MESTRAS E MESTRES DOS SABERES TRADICIONAIS
}

César Guimarães ${ }^{1}$

Pedro Aspahan ${ }^{2}$

\section{IMAGENS DA ESCUTA}

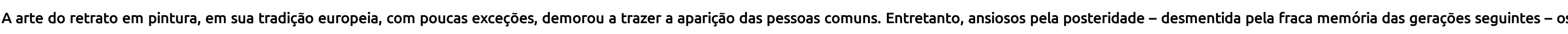

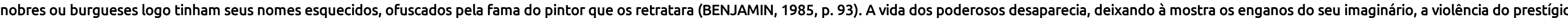

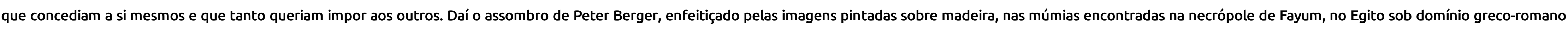

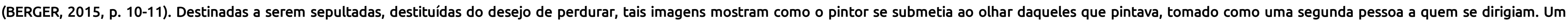

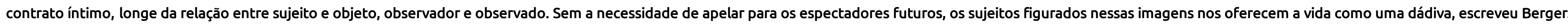

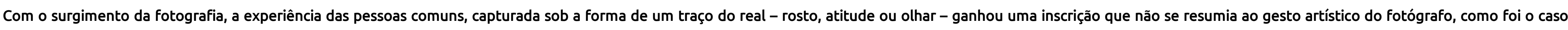

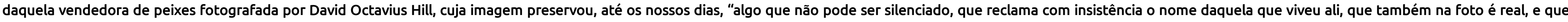

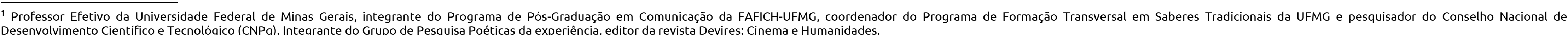

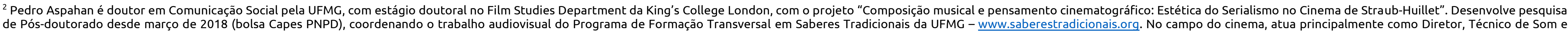

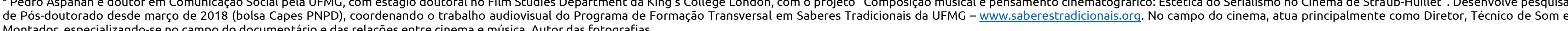
Montador, especializando-se no campo do documentário e das relaçoes entre cinema e música. Autor das fotografias. 


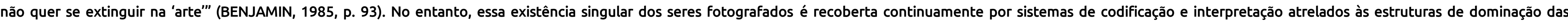
sociedades, que regulam e conduzem nosso olhar a partir de uma herança iconográfica por meio da qual essas relações se inscrevem na imagem.

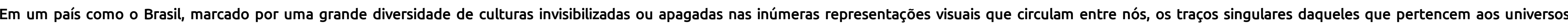
afrodescendentes, indígenas e populares são frequentemente ameaçados pela idealização ou pela exotização, em estratégias reificadoras que expropriam a identidade dos sujeitos retratados (HERKENHOFF, 1994, p. 43-44).

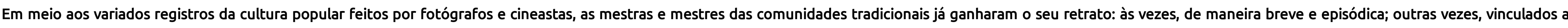

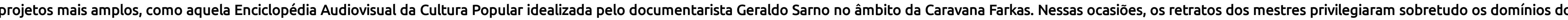
artesanato, das manifestações artísticas e religiosas, e as diferentes técnicas de trabalho.

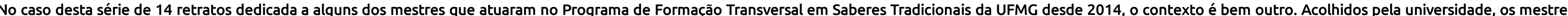

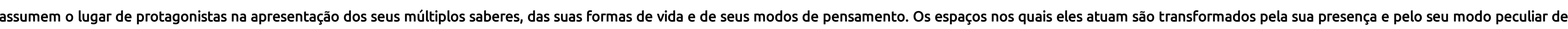

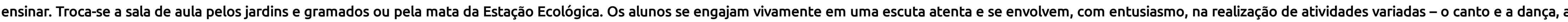
construção de casas indígenas, a feitura de tambores, pífanos e adornos com miçangas - que solicitam a participação plena dos sentidos e da inteligência, não mais separados (como é tão comum na vida acadêmica).

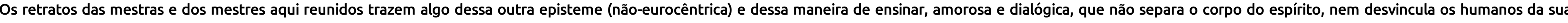

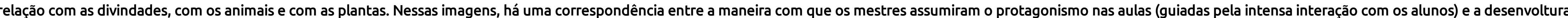

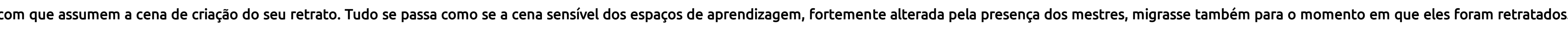

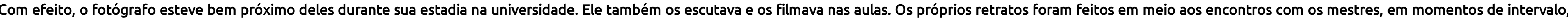

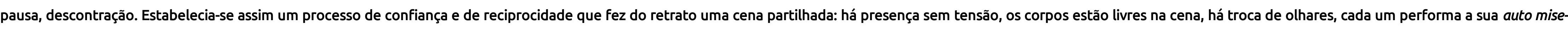
en-scène libertos da exigência de pose.

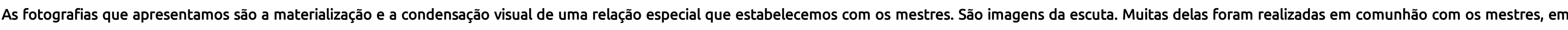

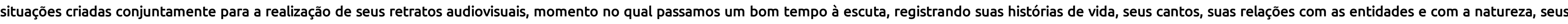




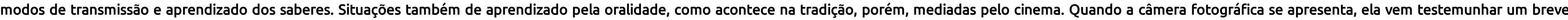
instante de partilha, um micro recorte temporal, cujo fora de campo se estende para várias dimensões da história e da relação que construímos continuamente com eles. Uma relação de escuta e de enorme aprendizado.

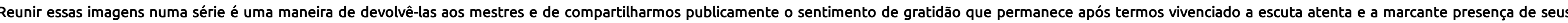
saberes tradicionais na universidade. 


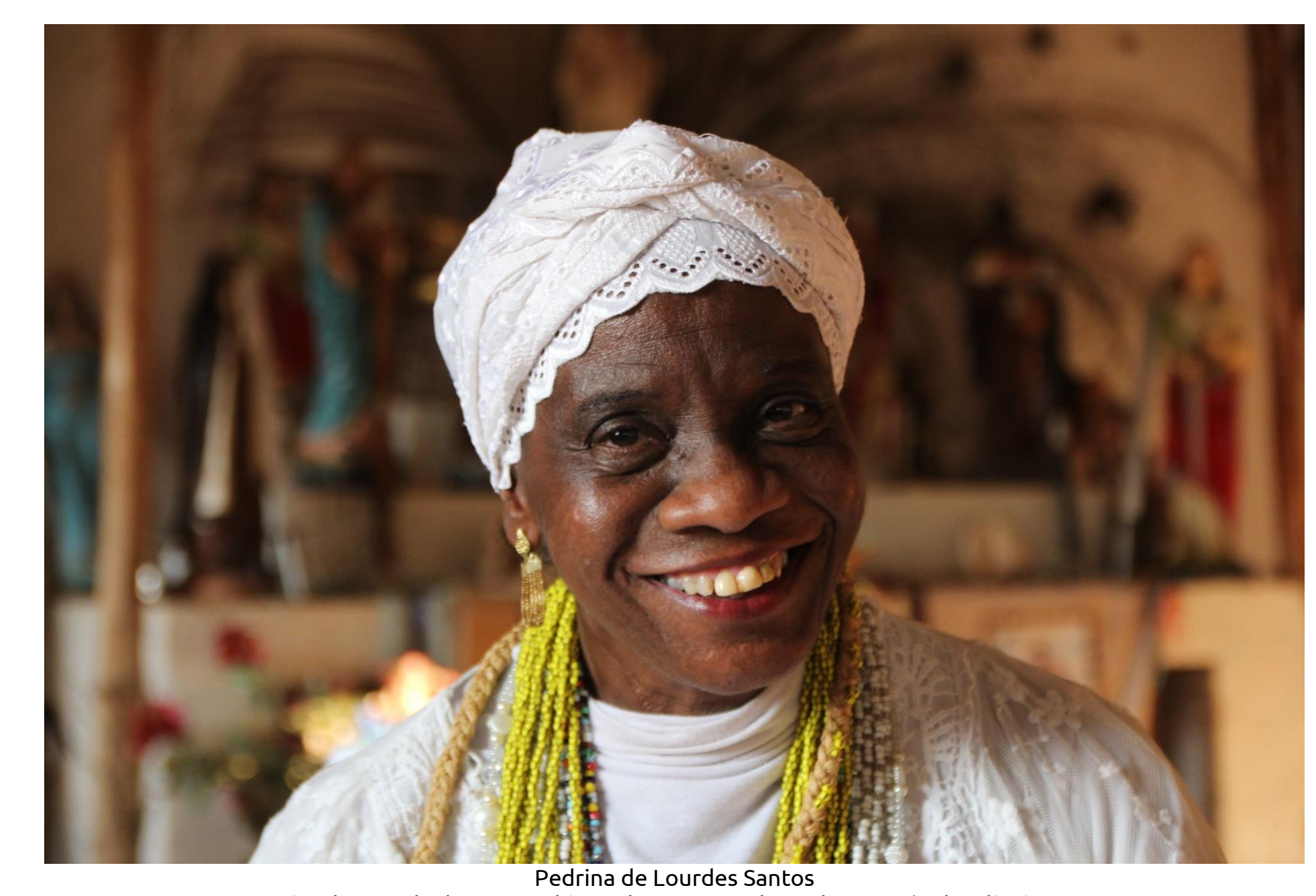

Capitã da Guarda de Massambique de Nossa Senhora das Mercês de Oliveira, MG 


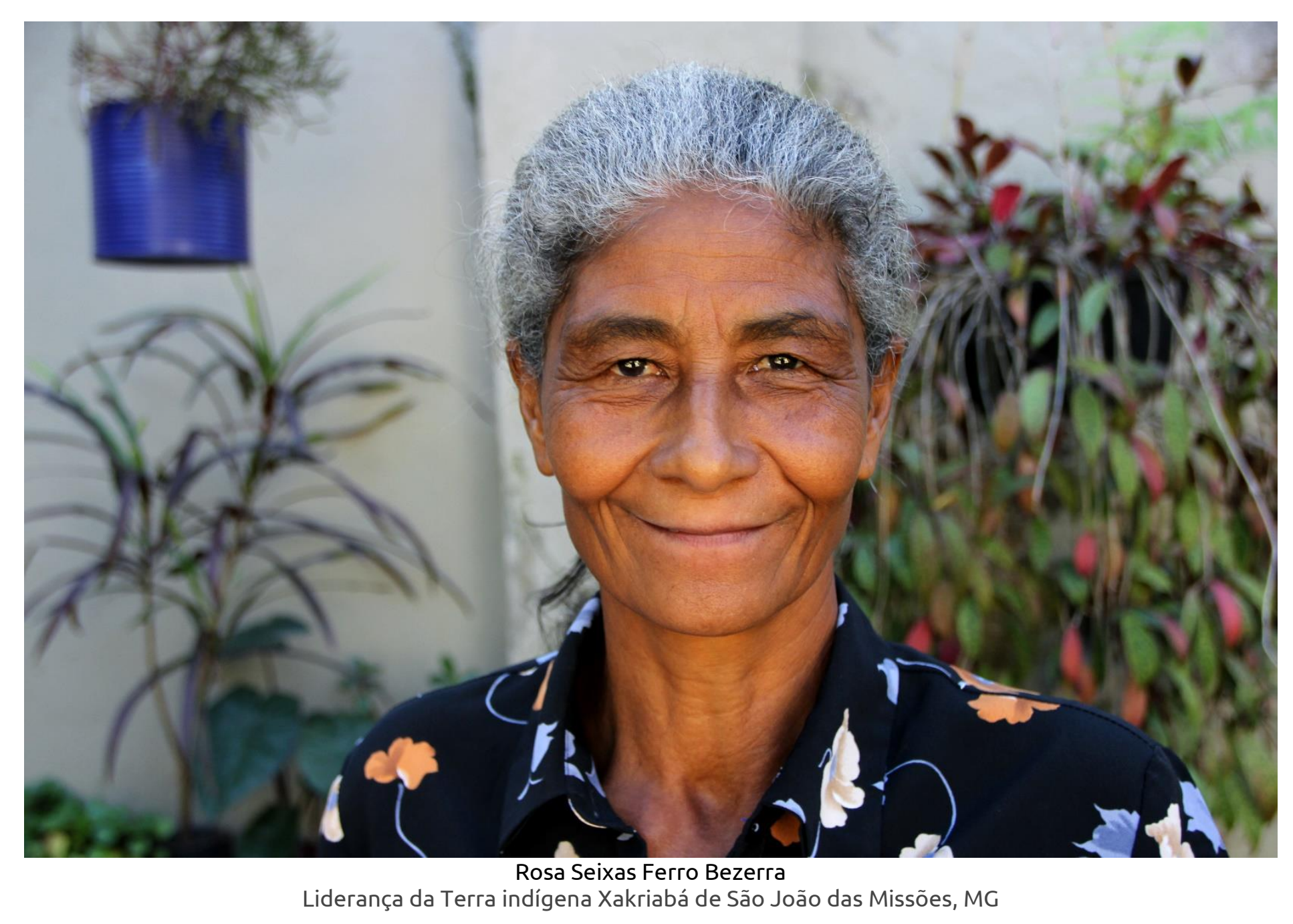




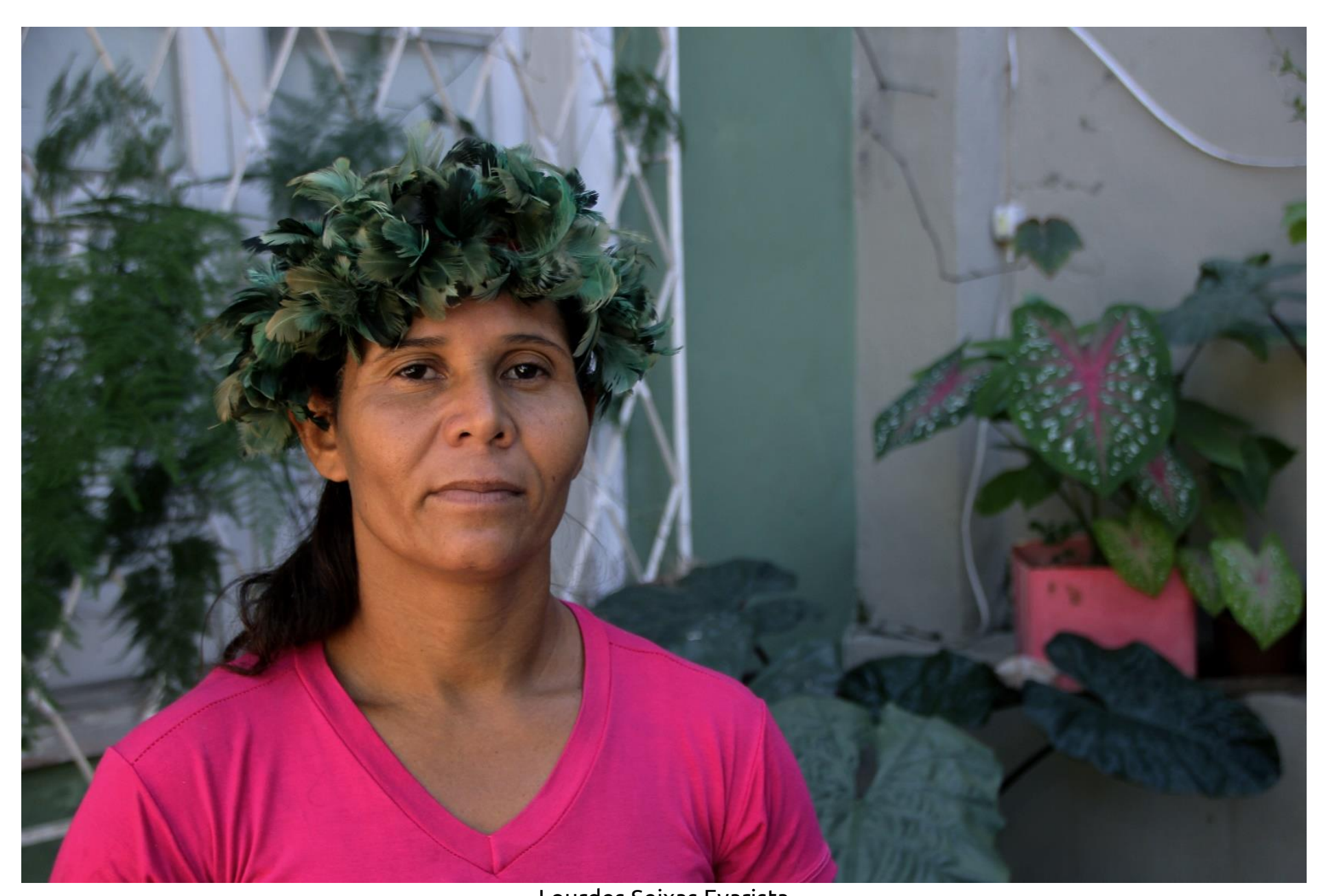

Lourdes Seixas Evarista
Liderança da Terra indígena Xakriabá de São João das Missões, MG 


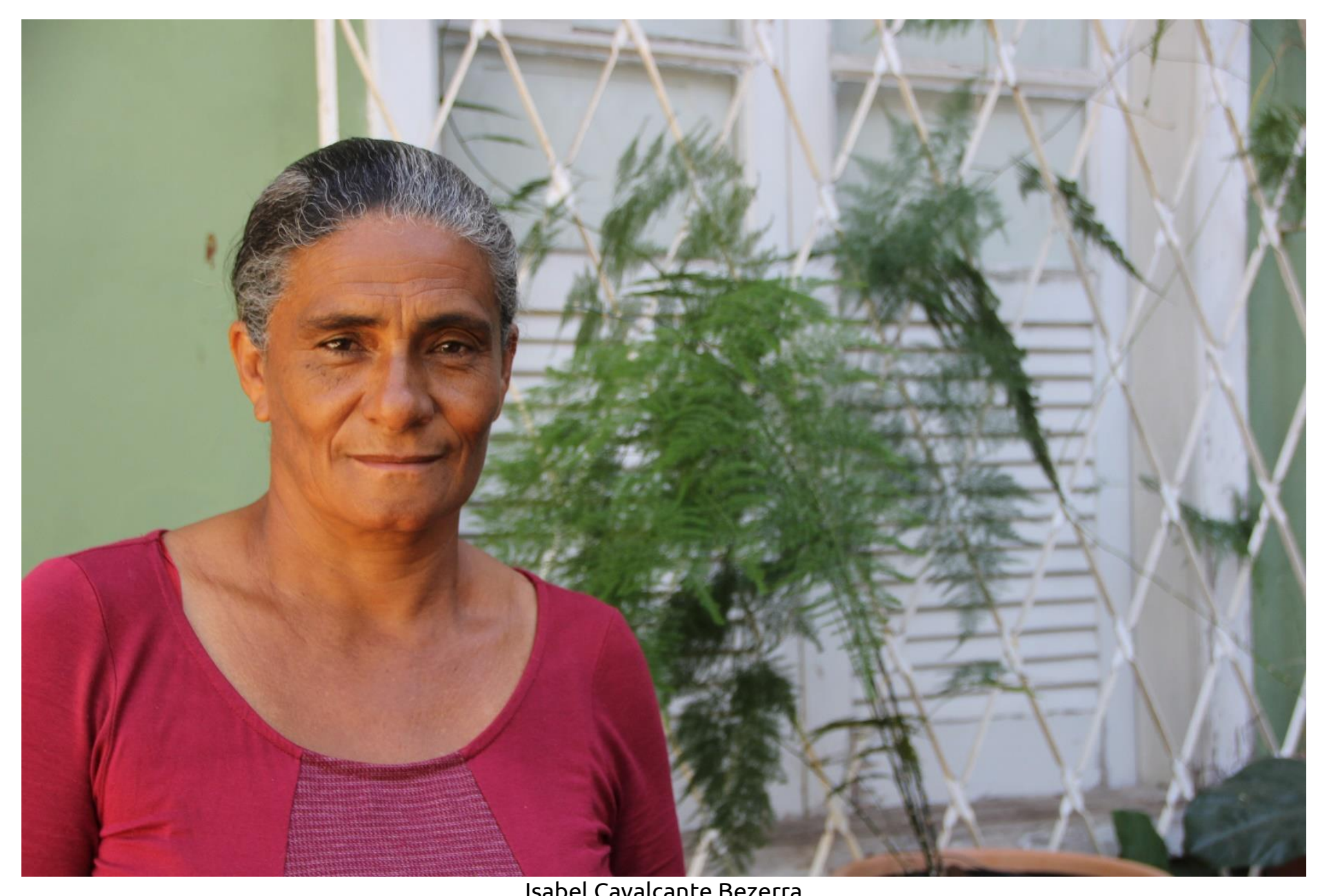

Isabel Cavalcante Bezerra
Liderança da Terra indígena Xakriabá de São João das Missões, MG 

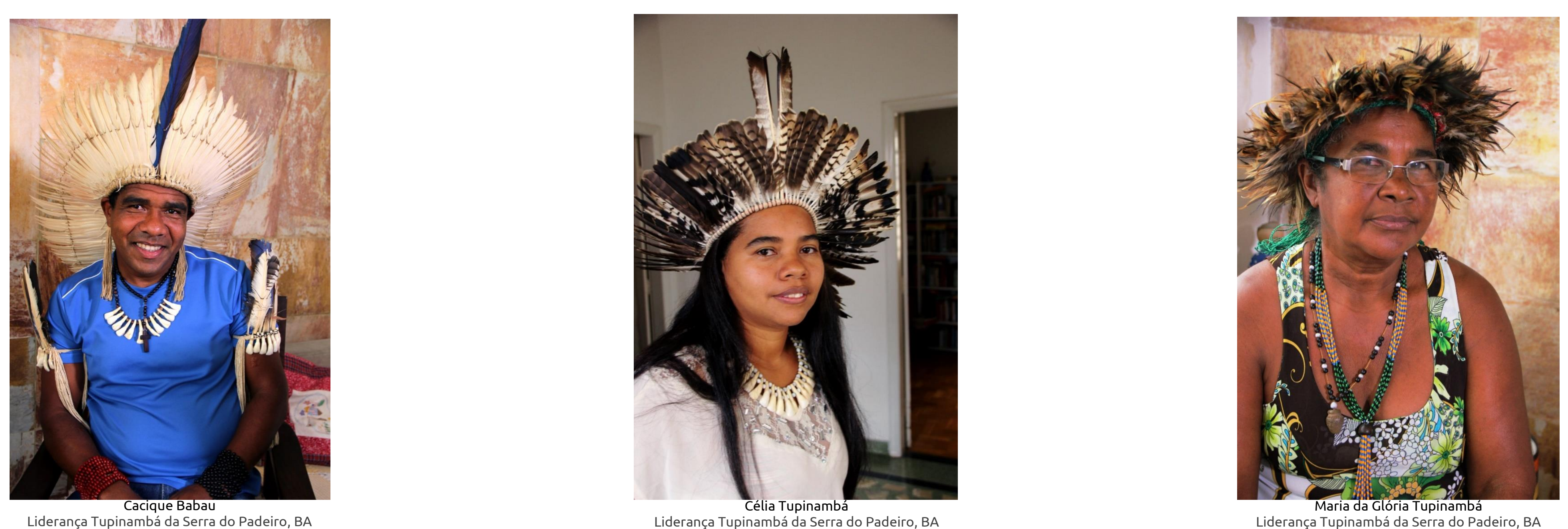


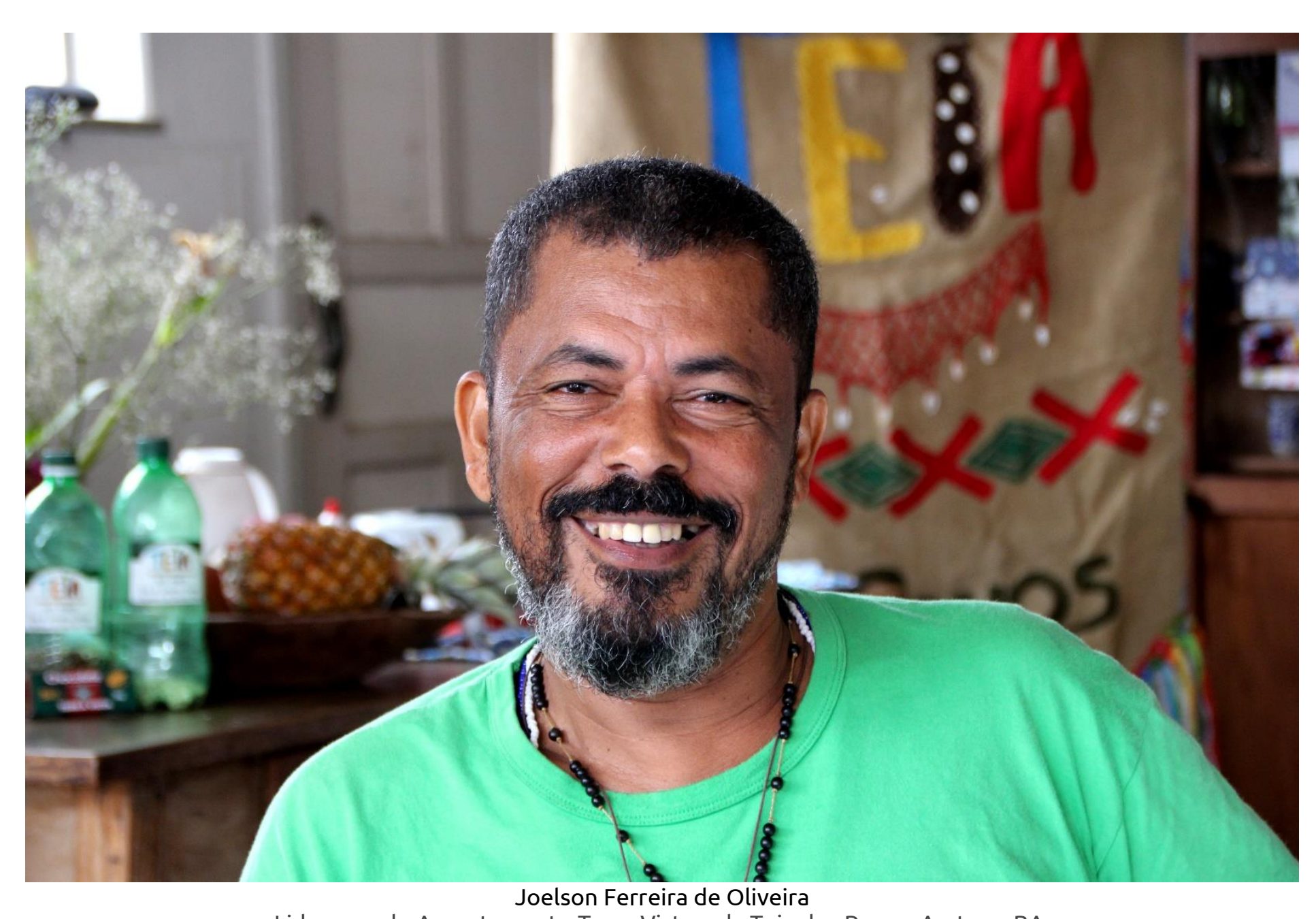

Liderança do Assentamento Terra Vista e da Teia dos Povos, Arataca, BA. 


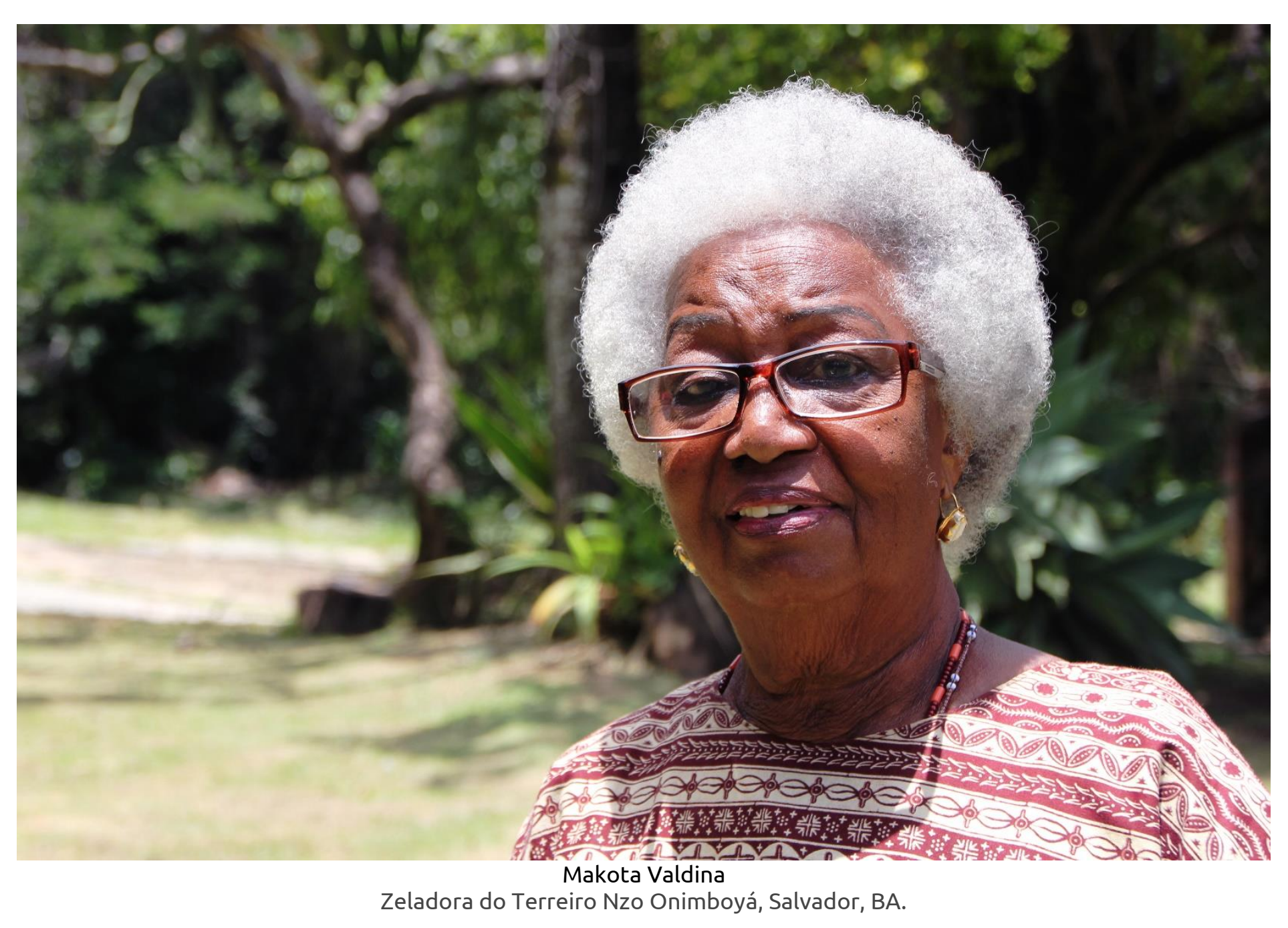




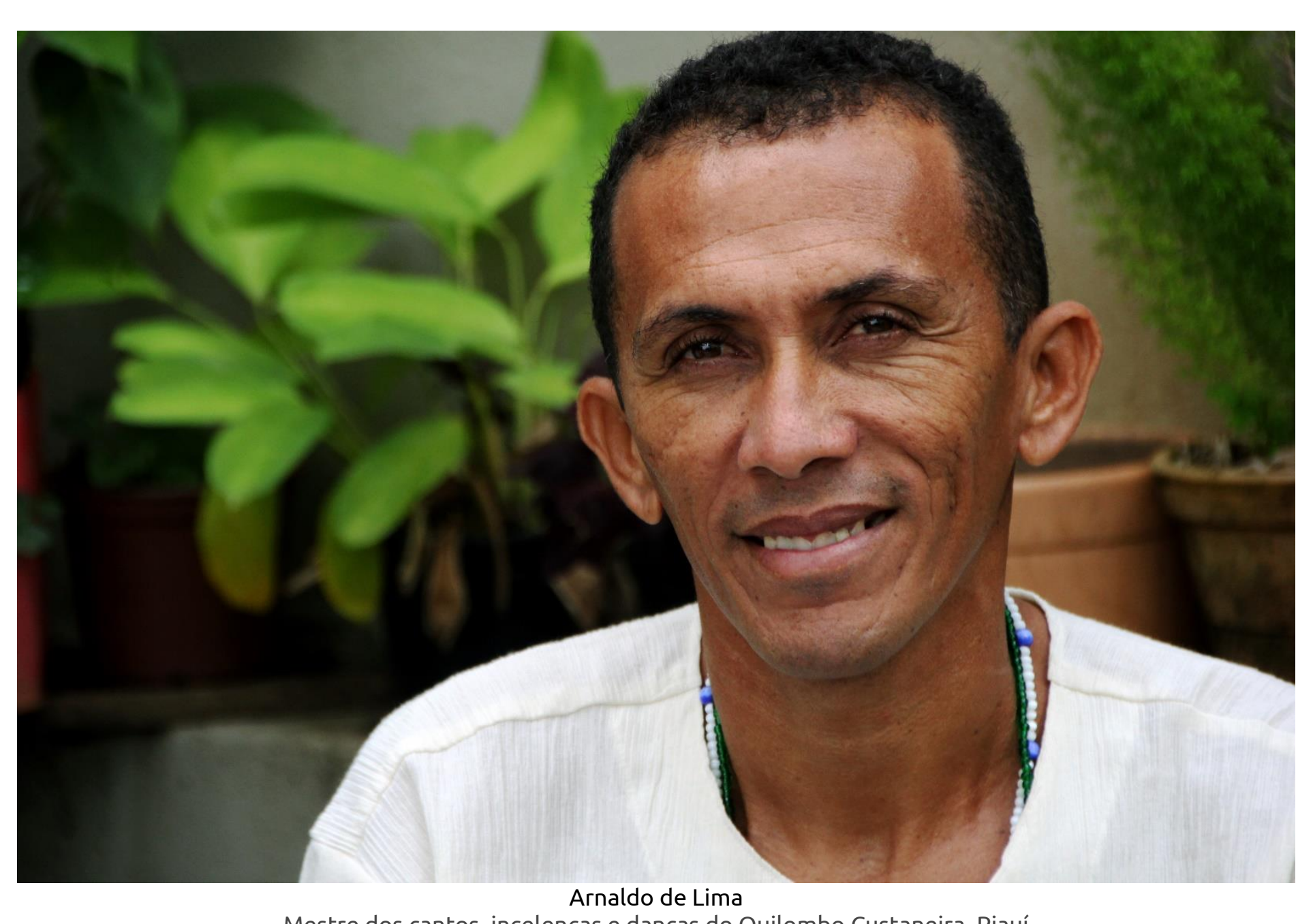

Mestre dos cantos, incelenças e danças do Quilombo Custaneira, Piaú 


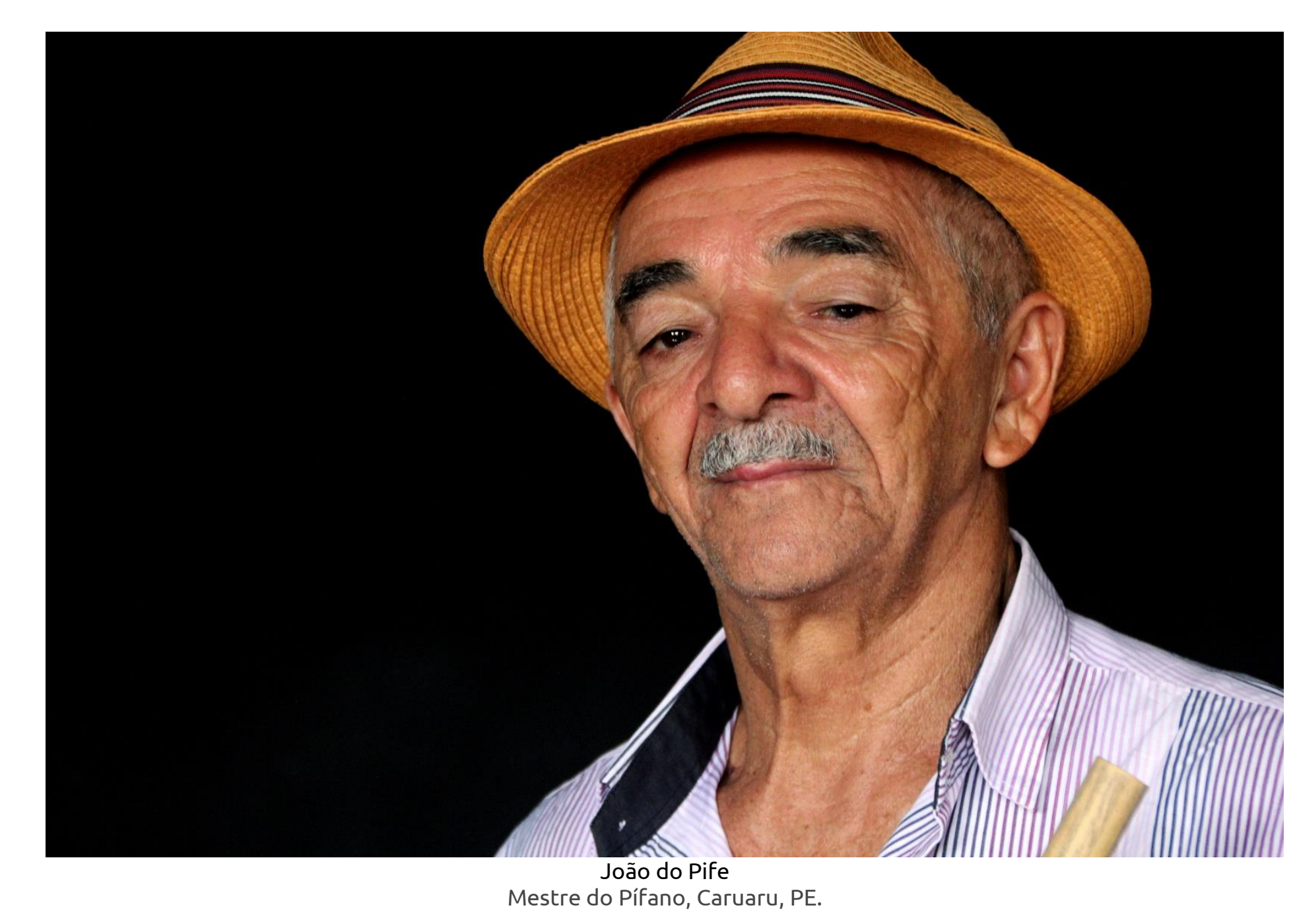




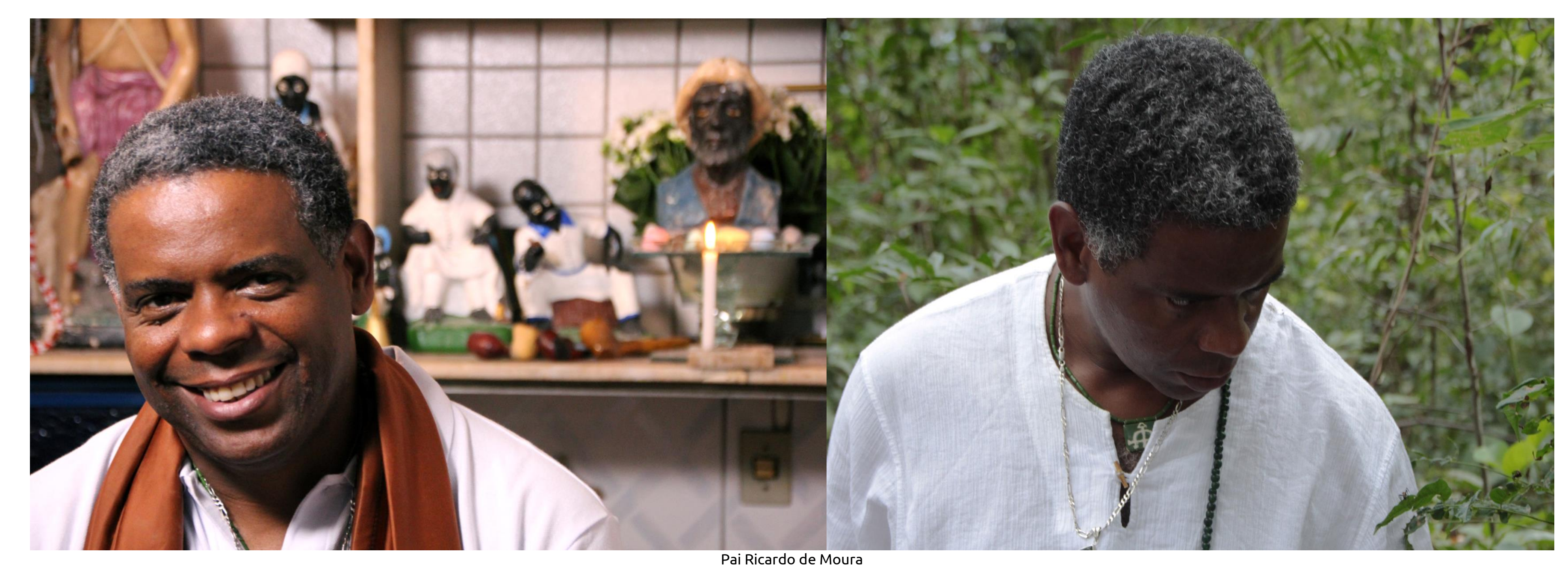

Zelador da Casa de Caridade Pai Jacob do Oriente, Belo Horizonte, MC 


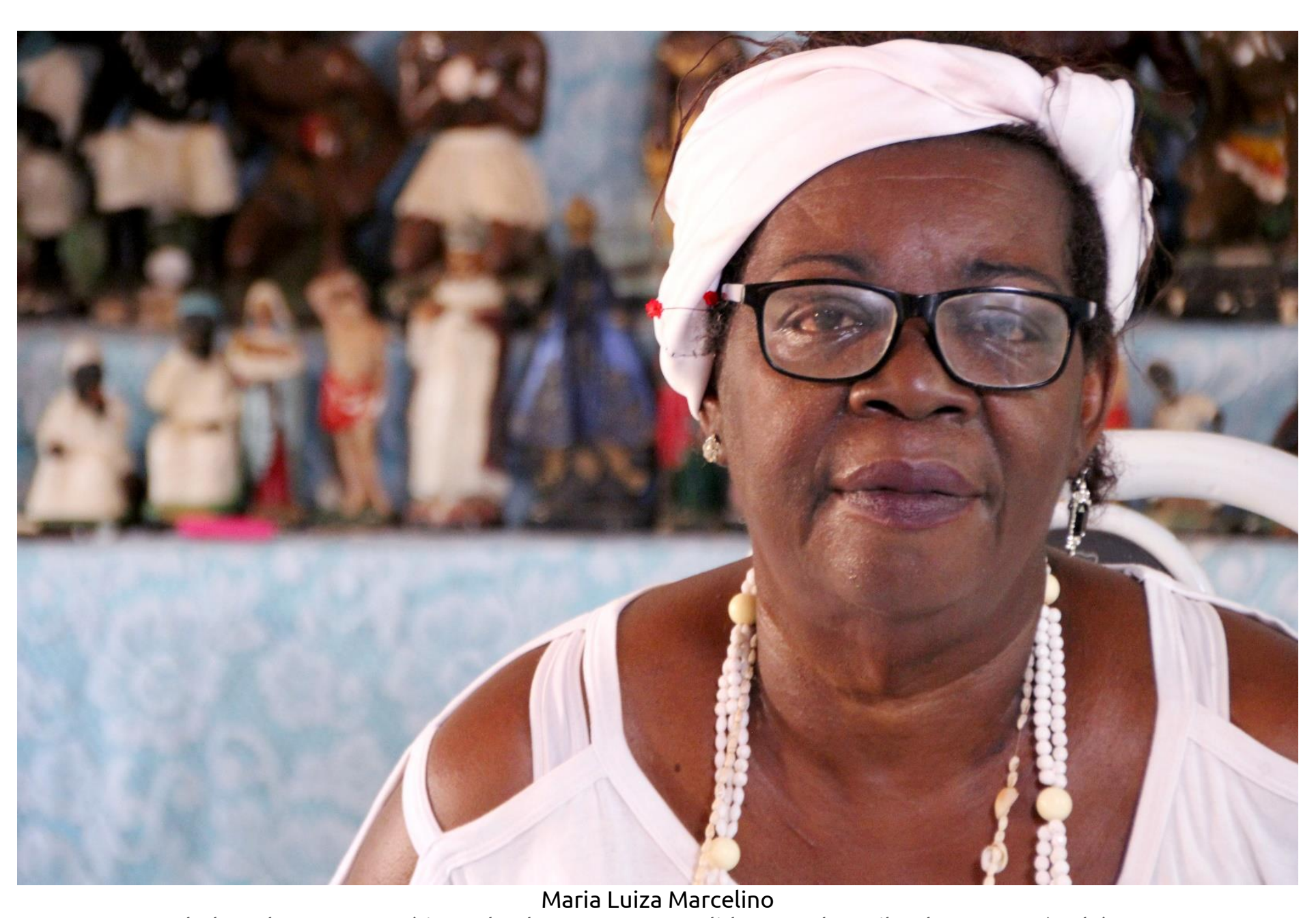

Maria Luiza Marcelino
Zeladora do Centro Espírito Caboclo Pena Branca e liderança do Quilombo Namastê, Ubá, MG 


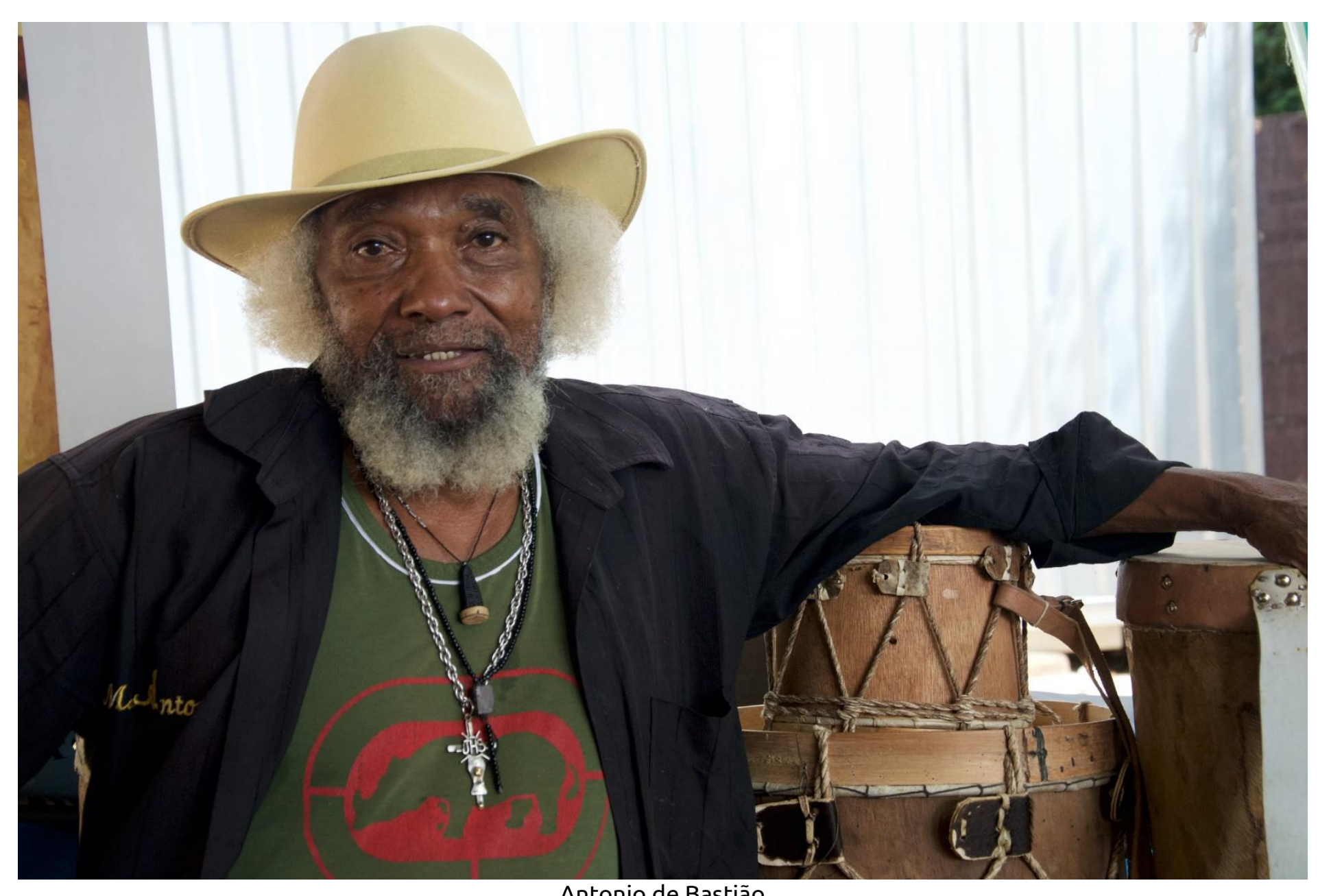

Antonio de Bastião
Mestre tamborzeiro do Quilombo de Macuco, São Benedito do Capivari, Minas Novas (MG) 
BENJAMIN, Walter. Pequena história da fotografia. In: BENJAMIN, Walter. Obras escolhidas. Magia e técnica, arte e política. São Paulo: Brasiliense, 1985

BERGER, John. Portraits: John Berger on artists. London-New York: Verso, 2015.

HERKENHOFF, Paulo. A espessura da luz: fotografia brasileira contemporânea. São Paulo: Câmara Brasileira do Livro, 1994. 